\title{
The Profile of Consumers of Food Supplements in Morocco
}

El Kartouti Abdeslam ${ }^{1 *}$, Youness Khalfaoui ${ }^{2}$

${ }^{1}$ Hospitalary Pharmacist Department, Faculty of Medicine and Pharmacy of Sidi Mohammed Ben Abdellah University in Fez, Morocco

${ }^{2}$ Médecin Généraliste Privé, Sidi Mohammed Ben Abdellah University in Fez, Morocco

DOI: $\underline{10.36348 / \text { sijtcm.2020.v03i06.002 }}$ | Received: 05.06 .2020 | Accepted: $17.06 .2020 \mid$ Published: 26.06 .2020

*Corresponding author: El Kartouti Abdeslam

Abstract

Introduction: The market of food supplements is in full expansion, this evolution is due to several factors in particular, nutritional deficiencies, sedentary, lifestyle and lower energy needs. Hence the interest in studying the consumer profiles of these products. Subjects and methods: This is a prospective study conducted over a period of eight months; subjects are recruited at random during our training, on the internet and during medical caravans whose objective is to assess the knowledge and practices of Moroccans so that the doctor can find concrete answers usable during his medical practice. Results: 570 subjects were included, of which 316 subjects $(57.1 \%)$ declared having already consumed food supplements. The study revealed the female predominance among consumers, as well as the predominance of the 20-30 year age group. Among the reasons for consumption, filling a deficiency comes first with (42.6\%), improved a particular function second with $(36.4 \%)$ and then treating an illness. For the essential expectations of consumers; fighting fatigue and fighting overweight come first with $34.8 \%$ and $14.1 \%$ respectively. The consumption of CA is most often done on the advice of a doctor with $(46.7 \%)$ and the pharmacy remains the main distribution channel with (78.7\%). Discussion and Conclusion: The regulatory framework for the marketing in Morocco of food supplements requires only the obtaining of a registration certificate. It is thus, the duty of each health professional to judge the benefit - risk of advising or prescribing a food supplement given the risks to which any consumer may be exposed.

Keywords: Food supplements, consumer profiles, consumption, benefit-risk.

Copyright @ 2020: This is an open-access article distributed under the terms of the Creative Commons Attribution license which permits unrestricted use, distribution, and reproduction in any medium for non-commercial use (NonCommercial, or CC-BY-NC) provided the original author and source are credited.

\section{INTRODUCTION}

Food supplements are foodstuffs whose purpose is to supplement the normal diet and which constitute a concentrated source of nutrients or other substances having a nutritional or physiological effect, alone or in combination. Their high consumption clearly explains the rapid evolution of their market; as consumers are more and more concerned about their health and are looking for these products, a way to make up for deficiencies (supposed or proven). To meet this demand, the food supplement has undergone development with real scientific rigor and invention marketing. The diversification of the offer has arrived to meet different expectations. Hence, the interest of our survey which aims to determine the profiles of consumers of food supplements in Morocco and to assess their knowledge and the practice of their prescriptions.

\section{SUBJECTS AND METHODS}

This is a prospective study whose purpose is to determine the profiles of consumers and to assess the knowledge and practices of Moroccans so that the doctor can find concrete answers that can be used in his medical practice. The survey was based on a questionnaire made up of 3 parts: the first part defines the food supplement and draws up a list of the different products available. The second part provides information on the socio-demographic status of the respondents. While the third part, relates to various information on the consumption of Food Supplements, in particular the methods of consumption (occasionally, regularly, frequently), the place of purchase, the components (vitamins, minerals, plants, others), the motivations of 'purchase (medical prescription, advice from a loved one, or out of curiosity), the goals sought by consumption (fight against fatigue, solving a health problem, etc.) 
Our survey included 570 subjects from the Moroccan population over an eight-month period. The recruitment of subjects was carried out actively in different regions thanks to a network of doctors who participated in the dissemination and collection of information and during the participations in human medical caravans, which made it possible not to target the population from one region.

The statistical analysis of the data was carried out using the "Google Drive" software. The results obtained related to: the description of the overall sample, the socio-demographic status of consumers, the characteristics of the consumption of food supplements. The last step involved comparing the results of the survey with data from the literature and proposing information and awareness-raising for healthcare professionals.

\section{RESULTS}

\section{Sociodemographic Data}

During the study period, 570 subjects were included, the sample is made up of 316 subjects $(57.1 \%)$ have already consumed food supplements, while $237(42.9 \%)$ have never consumed food supplements in their lives.

For the overall sample, $50.7 \%$ of the subjects were female and $49.3 \%$ male, while $35 \%$ of women consumed food supplements compared to $11 \%$ of men.

The distribution of consumers by region has shown that: it is in the regions, especially in the Center, especially in the cities of Fez, Meknes, Rabat and Casablanca, that there are the largest numbers of consumers, then the cities in the north. On the other hand, in the south the demand is almost nonexistent (Figure-1).

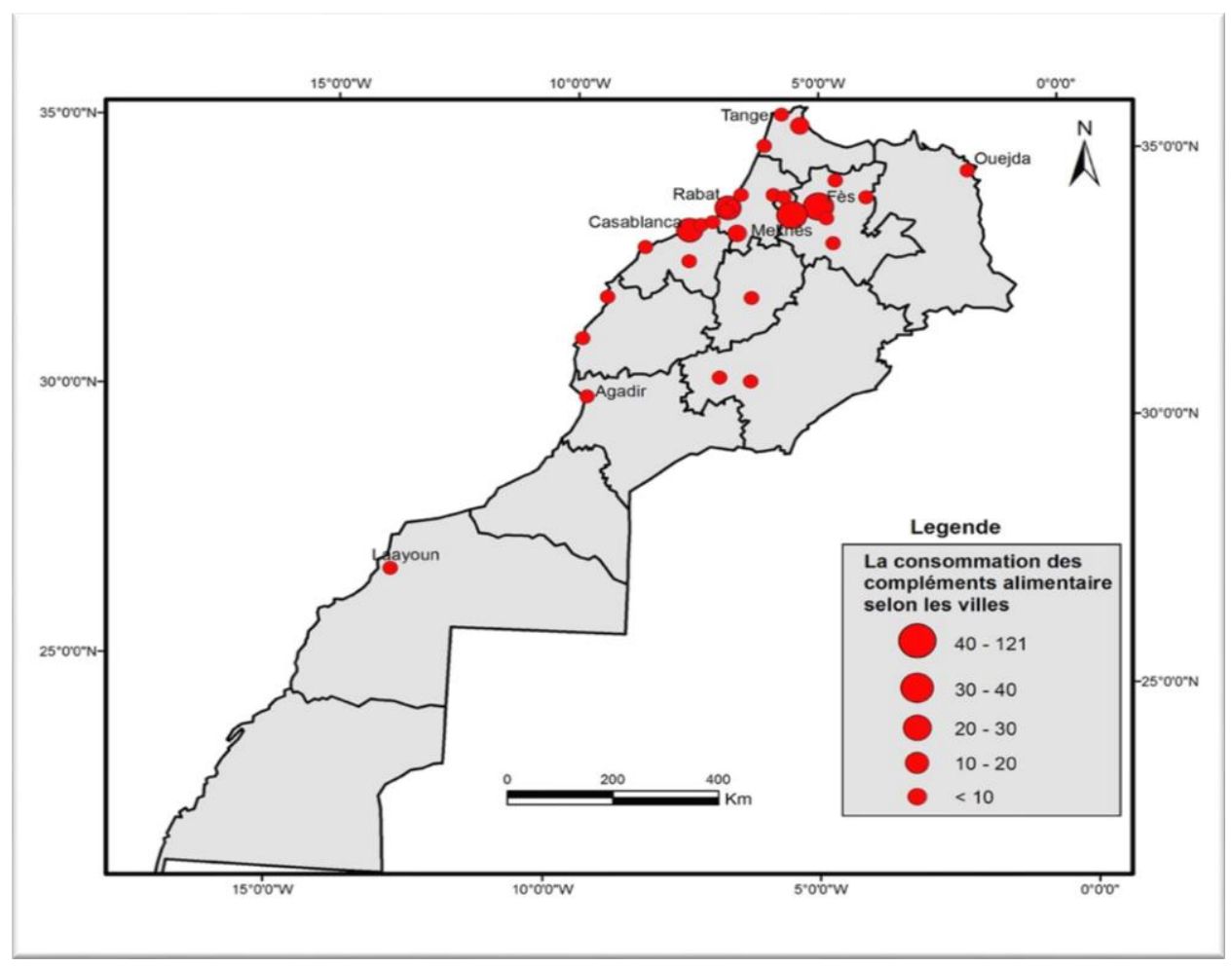

Fig-1: Distribution map of the consumption of Food Supplements according to the cities

The distribution of consumers by age revealed that: more than half or $51.7 \%$ of consumers of food supplements belong to the age group between 20 and 30 years old; $26.4 \%$ were in the $30-40$ age group; $8.70 \%$ were in the $40-50$ year age group; $8.10 \%$ were under 20 years of age; on the other hand $5.10 \%$ were 50 years and over.

Analysis of the professional status of food supplements consumers shows that: students and civil servants are the most consumers with around $68 \%$ of cases, then executives with a percentage of $24.3 \%$, and finally subjects without profession with a percentage of $7.8 \%$ only.

\section{Characteristics of the consumption of food} supplements:

Categories of food supplements most consumed by Moroccans:

It is most often a high consumption of vitamins $(43.9 \%)$, trace elements $(22.3 \%)$, then energizers $(7 \%)$, followed by minerals $(6.6 \%)$, intestinal transit regulators and omega $3 \mathrm{~s}$ in the same row with a percentage of $4.9 \%$ (Figure-2). 


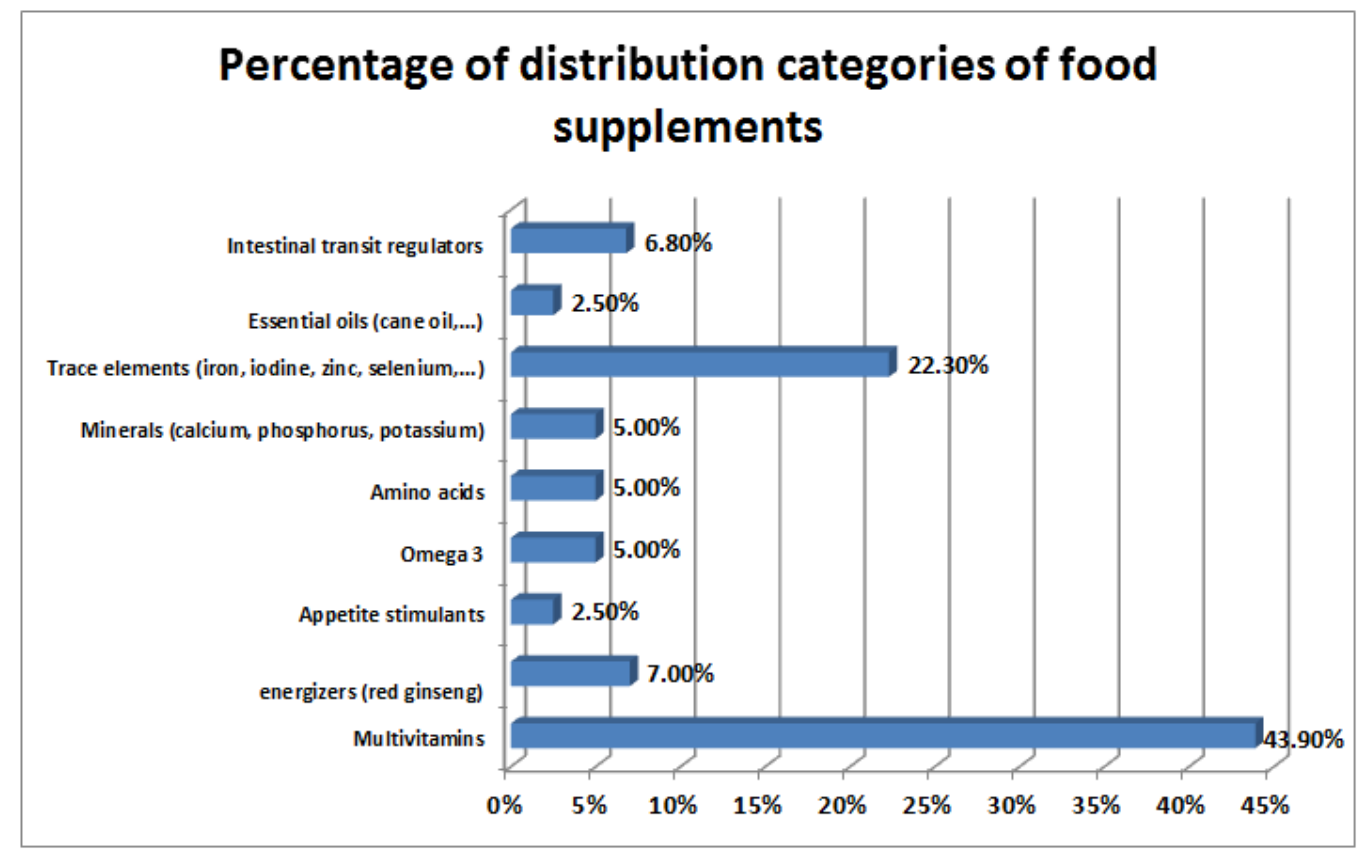

Fig-2: Categories of food supplements most consumed by Moroccans

Expectations with regard to the consumption of food supplements

The reasons given for taking food supplements are: filling a deficiency first (42.6\%), improving a particular function second $(3.4 \%)$, then treating an illness. The essential expectations for consumers are: fight against fatigue and overweight with a percentage of $34.8 \%$ and $14.1 \%$, then fight against anemia, overweight and transit disorders with respective percentages of $9.9 \%-8.9 \%$ and $7 \%$ (Figure-3).

\section{Percentage of distribution Motivations for the consumption of food supplements}
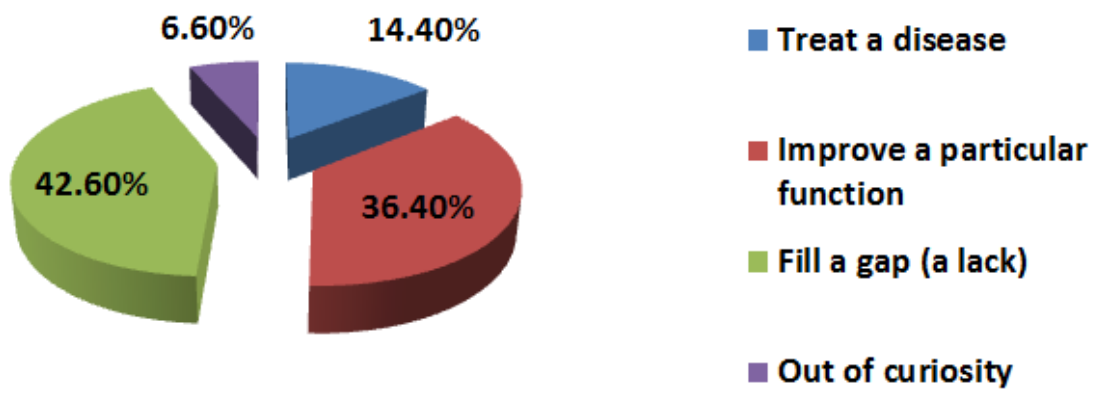

Fig-3: Motivations of Moroccans for the consumption of Food Supplements

\section{Circumstances of purchase of food supplements}

Food supplements consumption is most often done on the advice of a doctor with a percentage of $4.7 \%$, then self-medication with a percentage of $38.4 \%$, then the advice of a loved one with $8.7 \%$ of cases and the advice of a pharmacist last with $6.20 \%$.

\section{Places of Purchase}

The distribution channel that clearly increases in this equation is the pharmacy with a percentage of $78.7 \%$ then the Para pharmacy of $12.9 \%$, the internet of $5.4 \%$ and finally the big box stores of $3 \%$.

\section{Regularity of Consumption}

Among food supplements consumers, $79.5 \%$ of them were occasional users, $14.6 \%$ regularly and $5.9 \%$ frequent users (Figure-4). 


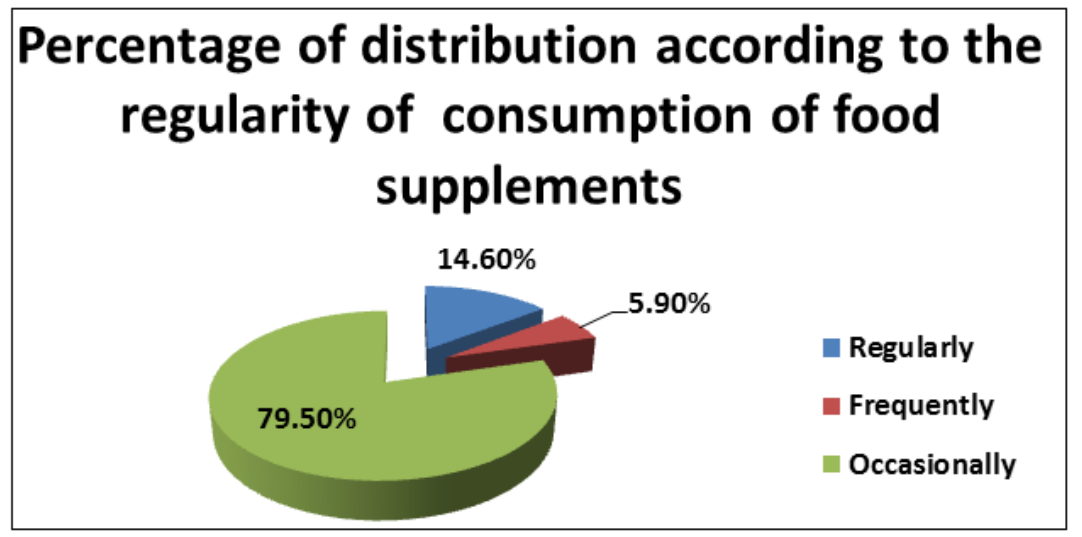

Fig-4: Percentage of distribution according to the regularity of consumption of Food Supplements

The daily dose of the food supplement

The majority of consumers respect the daily dose with a percentage of $82.9 \%$ and only $17.1 \%$ of cases do not respect it.
Satisfaction with the use of food supplements

$61.4 \%$ of the subjects seem satisfied with their consumption and $27.8 \%$ of the cases declare that the consumption of food supplements met their expectations against a low rate of dissatisfaction $10.8 \%$ (Figure-5).

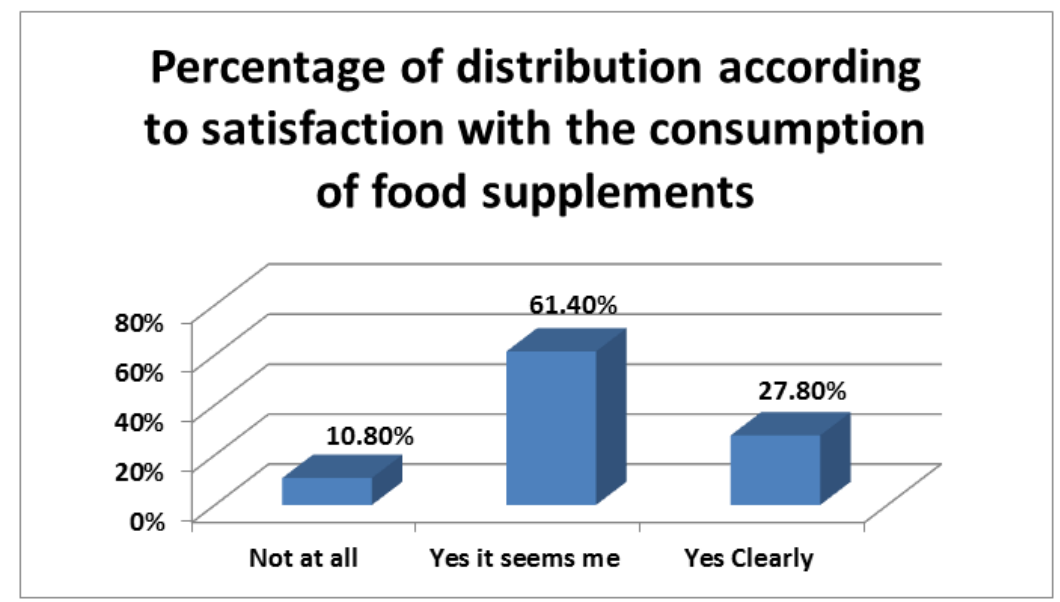

Fig-5: Percentage of distribution according to Satisfaction with the consumption of Food Supplements

\section{Food supplement and medication}

$22.6 \%$ of the cases are not aware of the probable risk of interaction between the food supplement and the drug, while $27 \%$ of the subjects are aware of this problem whereas, $22.6 \%$ answered that it is probable and $27.8 \%$ do not know (Figure-6).

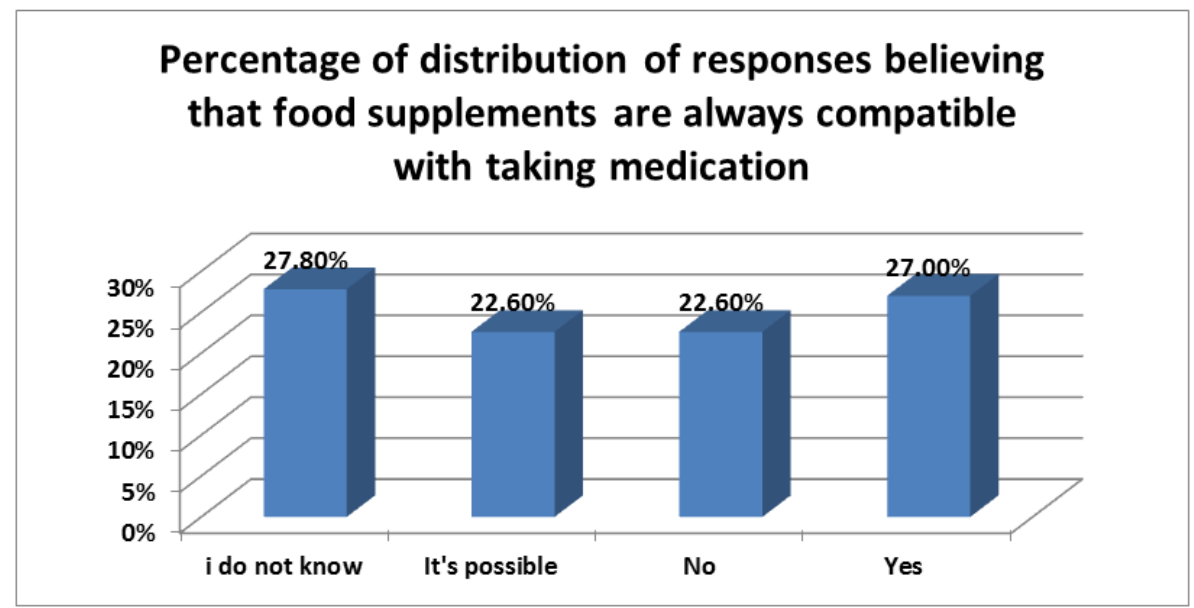

Fig-6: Percentage of distribution of responses believing that food supplements are always compatible with taking medication 


\section{DISCUSSIONS}

The attention paid to the balance of meals has become a significant factor in the choice of food. Behaviors are influenced by the health and nutritional recommendations of doctors, which are increasingly reported by the media.

Food supplements make it possible to avoid certain deficiencies or to meet specific needs (infants and children; women; sports or other activity), the enrichment of certain foods can also make it possible to fill in deficiencies. Thus, Morocco is among many countries which enrich the salt with iodine in order to prevent cretinism and goiter. This explains the growing trend in the consumption of food supplements.

These food supplements have only had legal status since the advent of European Directive 2002/46 / EC. This directive initiated the construction of a specific regulatory framework, such as to offer consumers products whose composition does not present any danger and which are labeled appropriately, so that they can make their choice with full knowledge of the facts [1]. Thus, these food supplements are defined as "foodstuffs whose purpose is to supplement the normal diet and which constitute a concentrated source of nutrients or other substances having a nutritional or physiological effect, alone or in combination, marketed in the form of doses., namely forms of presentation such as capsules, lozenges, tablets, pills and other similar forms, as well as sachets of powder, ampoules of liquid, vials with dropper and other forms analogues of liquid or powder preparations intended to be taken in measured units of small quantity [2-4].

Since 2007, the European Food Safety Authority (EFSA) has been responsible for assessing health claims before placing on the market and the European Commission establishes the register of authorized claims.

\section{The difference between food supplement and drug}

The difference between a food supplement and a drug lies in the fact that the drug is defined: "as any substance or composition presented as having curative or preventive properties with regard to diseases, as well as any product which can be administered, with a view to to establish a medical diagnosis or to restore, correct or modify their organic functions [5]". To obtain marketing authorization, a drug must be the subject of long and complex studies, intended to assess its efficacy and toxicity. However, food supplements in the regulatory sense are not drugs and cannot replace them and do not require marketing authorization and constitute foodstuffs intended to supplement the diet and contribute to the maintenance and allow healthy individuals to remain healthy (Table-1).

Table-1: The difference between a drug and a food supplement

\begin{tabular}{|l|l|}
\hline Medication & Food Supplement \\
\hline Treat a disease, pathology & Maintains well-being, well-being, beauty \\
\hline Sick people & Healthy people who want to stay healthy \\
\hline Medical prescription & Individuals' choice to better manage their lifestyle \\
\hline Therapeutic properties & nutritional / physiological properties \\
\hline
\end{tabular}

Food supplements are available in many distribution channels. It seems interesting that consumers can benefit from personalized advice when purchasing food supplements from a health professional. The trivialization of these products potentially increases the risk of complications. It is therefore the duty of health professionals to remember that food supplements are not food and to raise awareness of the dangerous potential of such products used under poor conditions, hence the interest of our study.

The results of our survey of 570 people showed that the consumption of food supplements is widespread in Morocco. Thus, these data report that $57.1 \%$ of people in the survey have already consumed food supplements. In several countries, the equally high prevalence of food supplements consumption, for example in France, a survey carried out by the AFSSA shows that on 2,624 adults (18-79 years) and 1,455 children (3-17 years), that $15,7 \%$ of adults and $5.6 \%$ of French children consumed food supplements in the last 12 months of the study [6]. While two other French studies have also shown respective consumption prevalence of $20.6 \%$ [7] and $40.8 \%$ [8].

\section{The socio-demographic profile of consumers of food supplements}

The socio-demographic profile of food supplements consumers has shown that their demand varies by region. Thus, the cities of Fez, Meknes, Rabat and Casablanca have the highest number of consumers of food supplements in Morocco. It is highly likely that this distribution is influenced by the concentration of a large number of civil servants, managers and students in these cities on the one hand, and on the other hand, the role of doctors and pharmacists who are concentrated in these aforementioned cities.

In our series, consumers are on average younger with a percentage of $51 \%$ of the $20-30$ age group. A French study [7] and the AFSSA survey [6] confirm this trend with a clear predominance of the 18 24 age groups. 
In our study, consumers are mainly women with a percentage of $35 \%$ against $11 \%$ of men. Several studies on food supplements confirm this trend. Thus, the CREDOC study reports that $22 \%$ of women consume food supplements compared to $8 \%$ in men [9]. The prevalence of use by women according to the INCA 2 study is higher than that of men by approximately $40 \%$, versus $30 \%$ [6]. These data confirm that the female sex appears to be a very influential factor in the consumption of food supplements.

Compared to non-consumers, supplement users were more educated, had higher socio-economic status and were more active [8-11]. Other data from the literature also confirmed these results [12]. Our study also proves that professional status has a positive influence on food supplements consumption, students constitute the most consuming category of food supplements with around $34.1 \%$; followed by the category of civil servants with $33.8 \%$. If the most educated subjects can be very sensitive to their health, they are also the ones who can more easily bear the cost of these products.

\section{Characteristics of the consumption of food supplements}

According to the results of our study, it is most often a high consumption of vitamins, trace elements, energizers and minerals. Vitamins and minerals experience a great variability in their complementary intakes, the largest contributions concerning vitamin D, vitamin B1 and vitamin C. Studies prove this trend where the nutrients most often consumed in the form of supplements were vitamin B6, vitamin C, zinc, magnesium and iron, while $\Omega 3$ and herbal supplements were fairly low in consumption $[4,8]$. We therefore note the primordial place of multivitamins, energizers and trace elements in the CA market (Table-2).

Table-2: Percentage of consumption of the most consumed food supplements

\begin{tabular}{|c|c|c|c|}
\hline Studies & $\begin{array}{l}\text { French Study (Th. } \\
\text { Pilorin) [4] }\end{array}$ & $\begin{array}{l}\text { French Study } \\
\text { (C.POUCHIEU) [8] }\end{array}$ & Our study \\
\hline $\begin{array}{l}\text { Most consumed food supplements } \\
\text { and percentage calculated at the level } \\
\text { of the population of consumers. }\end{array}$ & $\begin{array}{l}\text { vitamin D }(37 \%) \\
\text { vitamin B1 }(32 \%) \\
\text { vitamin C }(30 \%)\end{array}$ & $\begin{array}{l}\text { Magnésium }(42,1 \%) \\
\text { vitamin B6 }(29,8 \%) \\
\text { vitamin C }(27,2 \%)\end{array}$ & $\begin{array}{l}\text { vitamin }(43.9 \%) \text { trace elements } \\
(22.3 \%) \\
\text { énergizers }(7 \%) \text {, minérals }(6.6 \%)\end{array}$ \\
\hline
\end{tabular}

For men and women, the three essential purchasing and consumption expectations, which account for $70 \%$ of the responses, are: the fight against fatigue, the resolution of specific health problems and the fight against diseases [6]. Thus, a French study [8] shows that the expectations of purchasing and consuming supplements are also Combat fatigue and stay healthy.

For our study, the expectations mentioned for taking CA are: filling a deficiency first; improving a particular function in the second and after treating a disease, this confirms that health and appearance is a rapidly increasing concern among consumers.

The motivations and the circumstances of purchase of food supplements, according to our study shows that the consumption of food supplements is often done under the advice of a doctor with a percentage of $46.7 \%$, self-medication comes in second position with a percentage of $38.4 \%$, then lastly the advice of a loved one $(8.7 \%)$. These results were similar to those of the INCA 2 study [6], in which prescription or medical advice accounted for $52 \%$ of purchases. The food supplement generally remains advised by a health professional [13].

The acquisition of food supplements is greatly facilitated by over-the-counter sales in pharmacies, supermarkets or on the Internet. Data obtained from the Union of Dietetics and Food Supplements in 2015 and $2016[14,15]$, show that the pharmacy remains the first sales channel for food supplements in France, ahead of direct sales on the internet, specialized stores, large and medium-sized stores, and drugstores. These data are consistent with those found in our study, of which $78.7 \%$ of consumers buy food supplements directly in pharmacies, which is reinforced by the sales advice provided by pharmacists to customers, then come Para pharmacy and online shopping are however very rare. For the regularity of food supplements consumption, in our study there is a clear predominance of occasional consumption with a percentage of $79.5 \%$. A French study reported that overall, this consumption was $43 \%$ occasional, in $24 \%$ of cases in the form of several cures per year and in $2 \%$ of cases daily use [16]. In our series only $27.8 \%$ of consumers show real satisfaction.

\section{The risks linked to the consumption of food supplements}

The general principles and general prescriptions of food law establish that: "all foodstuffs intended for consumers, including those presented as food supplements, must meet the obligations of safety, loyalty and information laid down by the regulations in force" [17]. Products placed on the market must be safe and bear adequate and appropriate labeling in order to guarantee a high level of consumer protection. Despite these provisions, several risks linked to the consumption of food supplements can be highlighted, in particular: the risk of overdose, for example in the United States, each year, approximately 23,000 people are hospitalized for chest pain or cardiac disorders, which have occurred following an overdose of food supplements and it is the Centers for Disease Control and Prevention and the FDA that raise the alarm and 
emphasize this risk [18]. Drug interactions can pose real dangers to patients. So the substances in supplements can interact with medications, including those available without a prescription. For example, calcium can disrupt the action of certain heart disease medications, some diuretics, and antibiotics from the cyclin and quinolone family. Sometimes the effects of food supplements add to those of drugs. For this reason, ginkgo, vitamin E and fatty acids, omega-3 should not be taken at the same time as aspirin or blood thinners, for example [19]. But Only $27 \%$ of consumers in our series are aware of these risks. It is therefore important that health professionals can promote a prevention message on the risks of misuse of unknown or unsuitable substances.

\section{CONCLUSION}

The use of food supplements has increased considerably in recent years. This trend responds to a real demand from consumers to be an active player in their health. These foodstuffs whose purpose is to supplement the normal diet and which constitute a concentrated source of nutrients or other substances having a nutritional or physiological effect, but are not drugs and cannot replace them. The consumer had the feeling of becoming an "expert" of his health, by the abundance of information available in particular on the Internet. The healthcare professional remains a key player. It is therefore the duty of each professional to educate the consumer on the benefit and the risk by taking food supplements.

\section{REFERENCES}

1. Peigné, J. (2016). Les compléments alimentaires. Lexis-Nexis, Droit pharmaceutique.

2. Peigné, J. (2017). Législation des produits diététiques et des compléments alimentaires. Endocrinologie - Nutrition, 2018-01-01, 15(1) :18.

3. Bureau, L. (2016). Plants, dietary supplements and nutraceuticals, a complex regulations. Actualites Pharmaceutiques, 55(561), 34-38.

4. Pilorin, T., \& Hébel, P. (2012). Consommation de compléments alimentaires en France: profil des consommateurs et contribution à l'équilibre nutritionnel. Cahiers de Nutrition et de Diététique, 47(3), 147-155.

5. Cynober, L. (2008). Complément alimentaire, alicament, médicament: Qui est qui? Ou faust revisité. Cahiers de Nutrition et de Diététique, 43(1), 15-21.

6. AFSSA (Agence Française de Sécurité Sanitaire des Aliments). (2009). Étude Individuelle Nationale des Consommations Alimentaires 2 (INCA 2)(2006-2007). Individual and National Study on Food Consumption, 2, 228.

7. Dubecq, C., Daniel, Y., Aigle, L., \& Bigard, X. (2014). Utilisation des compléments alimentaires à visée ergogénique chez les militaires français: prévalence et modes de consommation lors d'une opération extérieure. Science \& sports, 29(4), 188195.

8. Pouchieu, C. Compléments alimentaires: consommation et facteurs associés en population générale et dans des groupes spécifiquesmodulation du risque de cancer. Université Paris 13: Unite De Recherche En Epidemiologie Nutritionnelle. https://cel.archivesouvertes.fr/EREN/tel-01240541

9. Pilorin, T., \& Hébel, P. (2012). Consommation de compléments alimentaires en France: profil des consommateurs et contribution à l'équilibre nutritionnel. Cahiers de Nutrition et de Diététique, 47(3), 147-155.

10. Kennedy, E. T., Luo, H., \& Houser, R. F. (2013). Dietary supplement use pattern of US adult population in the 2007-2008 National Health and Nutrition Examination Survey (NHANES). Ecology of food and nutrition, 52(1), 76-84.

11. Pouchieu, C., Lévy, R., Faure, C., Andreeva, V., Galan, P., Hercberg, S., \& Touvier, M. (2013). P041 Consommation de compléments alimentaires pendant la grossesse et facteurs socioéconomiques, alimentaires et de mode de vie associés. Nutrition clinique et metabolisme, (27), S77-S78.

12. Mileva-Peceva, R., Zafirova-Ivanovska, B., Milev, M., Bogdanovska, A., \& Pawlak, R. (2011). Socio-demographic predictors and reasons for vitamin and/or mineral food supplement use in a group of outpatients in Skopje. Prilozi, 32(1), 127 139.

13. Hébuterne, X., \& Gerber, M. (2009). La journée de réflexion sur les compléments alimentaires. Nutrition clinique et métabolisme, 2(23), 47-48.

14. Tsui, B., Dennehy, C. E., \& Tsourounis, C. (2001). A survey of dietary supplement use during pregnancy at an academic medical center. American Journal of Obstetrics and Gynecology, 185(2), 433-437.

15. SYNADIET, Chiffres clefs 2015 du marché des compléments alimentaires en France IMS Health, IRI, Données fournisseurs, FVD, FEVAD, données distributeurs. Année 2015.

16. Devaux, S., \& Brisard, M. (2016). Consommation de compléments alimentaires chez les triathlètes: résultats d'une enquête régionale. Nutrition Clinique et Métabolisme, 30(2), 118.

17. Règlement (CE) no 178/2002 du 28 janvier 2002: www.eur-lex.europa.eu/legalcontent/fr/TXT/?uri=CELEX:32002R0178.

18. http://www.onssa.gov.ma/fr/onssa1/missions

19. Santé: compléments alimentaires et médicaments, peut-on les prendre en même temps? Poster dans Santé le $18 \quad$ mars 2016 www.plusminceplusjeune.org. 